\title{
Vida humana y conciencia en Ex 1,15-2,10. Un aporte desde la teología bíblica del Antiguo Testamento a la discusión sobre el respeto a la vida humana
}

\author{
Andrés Ferrada \\ PONTIFICIA UNIVERSIDAD CATÓLICA DE CHILE
}

La lectura reposada de Ex 1,15-2,10 en su contexto refrenda dos convicciones de la enseñanza moral católica. En primer lugar, la vida humana inocente es un bien fundamental sobre la cual los seres humanos no pueden disponer a su arbitrio, incluso quienes ejercen el poder en la sociedad. En segundo término, la no disponibilidad de la vida se capta en la conciencia, sagrario donde Dios se revela a todo ser humano.

El hecho de que ambas convicciones pertenezcan al legado del Antiguo Testamento pone de manifiesto que el respeto y la promoción de la vida humana son puntos neurálgicos de la respuesta creyente ante los intentos de disponer arbitrariamente de ella, desde la antigüedad hasta hoy. También señala la esencial continuidad del mensaje revelado acerca de la vida humana en ambos testamentos.

Estas convicciones las abordaremos en dos acápites. En el primero mostraremos cómo la salvación de los niños hebreos condenados a muerte por el faraón -en particular en el caso de Moisés- se debe, en realidad, a la acción de Dios en la conciencia de las mujeres que los salvan; el Señor es agente indirecto de su rescate. En el segundo, retomaremos ambas convicciones profundizando el mensaje teológico de Ex 1,15-2,10.

\section{Salvación de los niños hebreos, una obra divina indirecta}

Desde un punto de vista narrativo y canónico, el relato del nacimiento y rescate de Moisés (Ex 2,1-10) no se entiende adecuadamente sin tener en cuenta las medidas represivas del faraón contra los israelitas: Establecimiento de su esclavitud (Ex 1,8-14) y las dos órdenes genocidas contra 
ellos, el infanticidio de los recién nacidos varones hebreos, primero a las comadronas (Ex 1,15-21) y luego a todos los egipcios en general (Ex 1,22). En efecto, estas medidas motivan la exposición del niño Moisés y ofrecen, además, valiosas pistas para la comprensión del relato.

Una de estas señas es la mención de Dios en el episodio de las comadronas. Estas desacatan la orden infanticida del rey «porque temieron a Dios» (v.17) y logran confundir al faraón en una especie de juicio ${ }^{1}$. Este finaliza con la complacencia del Dios de Israel en la conducta de las desobedientes (vv.20-21).

Cuando los destinatarios leen Ex 2,1-10 tienen en mente la precedente intervención divina. Captan la analogía entre las matronas y la madre de Moisés, su hermana y la hija del faraón. También estas mujeres desoyen la orden del faraón (Ex 1,22); incluso la forma de trasgresión es muy parecida (Ex 1,16). En ambos casos la prescripción real contiene esencialmente lo mismo; además, son disposiciones estrechamente ligadas, pues el decreto final de exterminio de los niños hebreos es la reacción ante el fracaso de la orden infanticida precedente.

¿Puede considerarse, entonces, la salvación de Moisés una intervención divina? ¿Constituye un portento atribuible al Señor?

Ex 2,1-10 no describe una actuación divina directa. Tampoco trasluce un plan divino, ni siquiera una moción divina sobre las protagonistas en la salvación del bebé. Sin embargo, la disposición de los elementos narrativos concede a los destinatarios pistas suficientes para descubrir ahí la voluntad divina.

En efecto, la causa de la salvación del niño es la piedad de la hija del faraón. Viendo al niño, abandonado, indefenso, llorando dentro de una cesta (Ex 2,6); la princesa se conmueve: «Este es uno de los bebés hebreos». En sí misma, la exclamación no implica el conocimiento de la orden del rey, pero en su contexto actual la encierra ineludiblemente. El comentario de la princesa es también un signo claro y consciente de desobediencia. La princesa se rebela al faraón igual que las parteras. La explicación del nombre del niño confirma su actitud: «Porque lo saqué de las aguas» (Ex 2,10: kî min-hammayim məšîtihû). El verbo «sacar fuera» (mšh), núcleo de esta etimología, designa precisamente la acción opuesta a la descrita por el

1 B.S. Childs, The Book of Exodus, 17 define los vv.18-19 como una especie de acusación judicial. 
verbo «arrojar» (šlk), con el que se designa la acción prescrita en la orden genocida del faraón (Ex 1,22).

La concatenación de los episodios narrados en Ex 1,8-22 y 2,1-10 justifica que el lector atento establezca una analogía entre Ex 1,17 y 2,6: Si el Señor inspiró temor en las parteras (v.17), también infundió piedad en la hija del faraón para salvar al niño².

Además, en las intervenciones de la madre natural y de la hermana mayor de Moisés vale la misma analogía: el Señor sostiene ocultamente los sentimientos naturales de madre y hermana. Una misteriosa acción divina les infunde fuerzas suficientes incluso para arriesgar su vida, al desafiar la orden del faraón apareciendo ante su hija (Ex 2,7-10a). En la óptica de los destinatarios la conducta de las mujeres no solo responde a sentimientos maternales, sino también se orienta a la fidelidad al Señor. Madre e hija encarnan la obediencia a la voluntad divina, tanto como la actitud de las parteras.

En síntesis, la salvación de los bebés hebreos, incluso el particular rescate del niño Moisés, hay que atribuirla indirectamente al Señor, que actúa misteriosamente en el interior de las protagonistas. Eso sí, la intervención divina en el caso de la salvación de Moisés solo se percibe en la atenta lectura del relato de Ex 2,1-10 en su contexto.

Pero nos preguntamos, ¿por qué en Ex 2,1-10 no se hizo más explícita la intervención del Señor? ${ }^{3}$, ¿por qué es necesario un proceso tan alambicado para acceder al papel que el Señor juega en la salvación de Moisés?

Una primera respuesta se enmarca en el fenómeno de economía narrativa. El compositor de Ex 2,1-10 no nombra al Señor, porque supone la inspiración divina del sentimiento de piedad maternal que recoge el texto. Da por supuesto que es algo evidente para el lector. Ex 2,1-10 se limita a lo esencial que quiere comunicar: la presentación de Moisés como

2 M. Greenberg, Understanding Exodus, 41 lo explica de modo diverso: las parteras necesitaban el temor a Dios para vencer el temor al rey; a la hija le basta la piedad para superarlo. La hija no temía las reacciones paternas. En la interpretación de Greenberg la piedad es un valor casi «carnal», desligada de una esfera más alta de valores. Esta visión contrasta con la piedad en el AT, donde suele vincularse al Señor. De hecho, el verbo usado en Ex 2,6 hml, «tener misericordia», tiene muchas veces al Señor por sujeto. P. ej.: 2Cr 36,15; Ez 9,10; 36,21; J1 2,18; Za 11,6; Ml 3,17.

3 J. Cohen, The Origins, 53 observa que Flavio Josefo atribuye explícitamente al Señor el rescate de Moisés; cf. Ant II 209.217-227. 
israelita de nacimiento y egipcio por adopción. La narración gira en torno a estos dos pernos, no a una intervención divina indirecta ${ }^{4}$.

Una segunda respuesta nace de la ubicación del relato en Ex 1-25. El material de estos capítulos ha sido cuidadosamente dispuesto y coordinado por el compositor que les dio su forma actual:

- Exposición del problema esencial del Éxodo: la liberación de los israelitas de la esclavitud de Egipto (Ex 1,10-22).

- Introducción de los protagonistas humanos del problema: los israelitas (Ex 1,1-7); el faraón y los egipcios (Ex 1,8-10), Moisés (Ex 2,1-22).

- Introducción de la intervención divina en la resolución problema: se deja para el final (Ex 2,23-25) ${ }^{6}$. Las alusiones a Dios de Ex 1,17.2021 no constituyen propiamente su aparición en escena, pues su actuación allí es indirecta. El Señor entra de lleno solo en los versículos conclusivos.

Por tanto, el compositor que le dio la forma actual a Ex 1-2 ha silenciado lo más posible las actuaciones de Dios antes de su aparición activa en una especie de querella ${ }^{7}$. El último versículo de Ex 2 deja entrever el

4 Si se considera que Ex 2,1-10 es un fragmento insertado en su contexto actual, esta explicación cobra mayor razón respecto al responsable de tal inserción. En efecto, le resultaba innecesario recordar la actuación divina; esta se desprende fácilmente de la analogía con Ex 1,17. Cf. A. Ferrada Moreira, Nacimiento de Moisés, 29-67.

5 Cf. A. Ferrada Moreira, Nacimiento de Moisés, 16.

6 En Ex 2,23-25, con todo, es presentado bajo el nombre común ’ělōhîm, «Dios». Esto se debe a que Ex 2,23-25 es un texto claramente perteneciente a P (cf. B.S. Childs, The Book of Exodus, 28), que reserva la revelación del nombre propio divino para Ex 6,3, cuando el Señor comunica su nombre directamente a Moisés.

Además, en la forma final del libro del Éxodo, la reserva del nombre propio divino hasta el relato de la vocación de Moisés (Ex 3,2.4.7.15...) tiene el mismo efecto narrativo. Esto explica por qué tampoco se usa el nombre del Señor en Ex 1,17.2021, espec. en el v.20.

7 Ex 2,23-25 emplea cuatro términos de querella o acusación en el A.T.:

- El verbo zcq, «gritar» (v.23): Ex 5,15; 22,22; 2Re 8,3; Is 19,20.

- Su sinónimo 'nḥ (en nifal; v.23) emparentado con el sustantivo ’ănāḥāh, «gemido»: Lm 1,22; S1 6,7; 31,11; 38,10.

- El sustantivo šaw ${ }^{\complement} \bar{a} h$, «clamon» o «petición de ayuda» (v.23): 1Sam 5,12; Sl 34,16; 145,19 y Jr 8,19.

- El sustantivo nə’āqāh, «gemido» (v.24): Ex 6,5; Jue 2,18 y Job 24,12.

Para más detalles véase P. BоvAT, Ristabilire la giustiz̨ia, 289-291. 
primer acto del juicio divino contra Egipto: $« Y$ viendo a los israelitas, Dios se interesó por ellos» (Ex 2,25).

En otras palabras: la disposición de los materiales de Ex 1-2 no es casual. El compositor reduce deliberadamente al máximo las menciones de Dios antes de su aparición final. De este modo resalta vigorosamente la primacía divina en la salvación de Israel $^{8}$.

\section{Mensaje teológico de Ex 1,15-20 y el respeto de la vida bumana inocente}

El contenido teológico de Ex 1,15-21 es claro. El Señor acepta y premia la desobediencia de las parteras: «Dios premió a las parteras: el pueblo crecía y se hacía muy fuerte, y a ellas, por haber temido a Dios, también les dio familia» (vv.20-21). A la recompensa precede el juicio aprobatorio divino"; la recompensa tiene su motivación: «Por haber las parteras temido a Dios» (v.21a). La explicación no es nueva para el lector. En efecto, el narrador ya la había anticipado en el v.17: «Las parteras temieron a Dios, y en vez de hacer lo que les había mandado el rey de Egipto dejaron con vida a los recién nacidos».

La mención del premio invita al lector a valorar justamente la conducta de los protagonistas. Sus acciones tienen una profundidad encubierta por las simples apariencias. Los acontecimientos humanos hacen referencia a un plano superior de relaciones personales. En ellas, el ser humano se relaciona con el Señor. Un Dios oculto, pero presente. En una palabra, los eventos humanos no le son indiferentes. El Señor los valora, los juzga; y además en su ejecución o incumplimiento deja sentir su presencia.

La desobediencia de las parteras sugiere que el temor divino no es, en realidad, una iniciativa humana, sino una respuesta. Es obediencia a un tú perso-

8 E. BLum, Studien, 10: «Diese indirekte, "gebrochene" Darstellungsweise [von Gott] hat zudem ihren guten erzählerischen Sinn: Zunächst für den Kontext, bilden doch Ex 1f. damit den kontrastiven Hintergrund, vor dem die Gottesoffenbarung in Ex 3(ff.) umso heller leuchtet; aber auch im Blick auf die Handlung selbst, da für die Israeliten unbeschadet des verborgenen Handeln Gottes die erlittene Bedrückung unverändert bestehen bleibt; es ist diese Erfahrung, die in der Erzählweise von Kap. 1f gleichsam abgebildet wird».

9 Recogiendo una reflexión no publicada del Prof. J.L. Ska: la recompensa divina de las parteras corresponde a la sentencia de una suerte de juicio que el faraón ha instruido contra ellas (sigue a B.S. CHILDs, The Book of Exodus, 17). Dios asume la función judicial en vez del faraón, que se ha revelado juez incapaz. De hecho, la astucia de las matronas se burla del rey. 
nal, misterioso, cuya voz exige el respeto de los valores humanos fundamentales. Con nueva profundidad, se capta porque el Señor puede ser considerado causa indirecta de la salvación de los inocentes. En otras palabras, el respeto de sus vidas no es una conquista humana merecedora del aplauso divino, sino una exigencia divina portadora de bendición a quien la observa.

Este diálogo íntimo con el Señor se desenvuelve en lo profundo del corazón humano -la conciencia-. Ahí el Señor hace sentir su temor, el respeto a lo absoluto, a lo indisponible a la decisión del ser humano. Las parteras se veían abocadas a atentar contra la vida inocente, invadiendo el campo sagrado de las decisiones divinas, para ellas inaccesible. Ellas experimentan el temor del Señor: desobedecieron la orden, porque «temieron a Dios» (v.17). El temor del Señor, por consiguiente, tiene contornos bien precisos. Es en términos modernos el respeto de los derechos y valores inalienables de la persona.

El relato no alude a revelaciones divinas o a preceptos sobre la vida inocente ${ }^{10}$. Éstos residen -están impresos- en la conciencia del ser humano. En este sentido resulta interesante la discusión sobre la nacionalidad de las parteras. Algunos autores las tienen por israelitas; otros, por egipcias. Esta última posición resalta el valor universal del temor de $\operatorname{Dios}^{11}$. De hecho, algunos textos veterotestamentarios reconocen el temor de Dios en los paganos (cf. Gn 20,11; 42,18; Job 1,1.8-10; Jon 1,10.16). Sin embargo, no es solo una actitud propia del extranjero, también se dice de algunos hebreos que temen a Dios: p. ej., Abraham (Gn 22,12) y los jueces elegidos por Moisés (Ex 18,21) ${ }^{12}$.

Ex 1,15-21 sugiere el modo de gobierno divino sobre el ser humano. El Señor practica un modo de juicio indirecto. Recompensa el temor de las parteras con una prolífica descendencia (v.21b). El faraón, solo puede esperar el destino contrario: la muerte (cf. Ex 2,23a).

Ex 2,1-10 prosigue a su modo el mensaje teológico de Ex 1,15-21 que expondremos a continuación.

Ya observábamos que las acciones de la madre de Moisés, de su hermana mayor y de la hija del faraón son reacciones análogas a las de las

10 P. ej., Ex 20,13 = Dt 5,17.

11 Cf., p. ej., T. RÖMER, «Les sages-femmes du Pharaon [Ex 1/15-22]», 267-269.

12 Para una discusión del argumento véase J.S. ACKERMAN, «The Literary Context», 8586. 
matronas hebreas. Ex 2,1-10 subraya cuidadosamente los sentimientos maternos de las dos madres de Moisés. La minuciosa fabricación de la cesta descubre el corazón de su madre natural (Ex 2,3aß); Ex 2,6b explicita la compasión de la madre adoptiva.

Dada su estrecha correspondencia con la desobediencia de las matronas, estas reacciones son espejo del temor a Dios. La doble escena femenina produce un díptico sugestivo: la resistencia de las parteras toma la forma de desobediencia pasiva a la orden del faraón; las segundas, más audaces, le oponen una desobediencia activa.

Además, en Ex 2,1-10 late como en Ex 1,15-21 el corazón de toda mujer: defender la vida del propio hijo y la de todo hijo, especialmente los más desvalidos y sufrientes.

A lo precedente se debe añadir una observación ulterior: en la actuación de las mujeres de Ex 1,15-2,10 resuena la presencia divina en la cotidianidad de los seres humanos. Tutelar valores humanos intangibles exige responder en la vida concreta a la voz del Señor que habla en lo profundo del corazón.

Concretamente, a las medidas genocidas las mujeres de Ex 1,15-2,10 se oponen con medios extremos: la trampa de las matronas, la actividad clandestina de la madre y la hermana del niño, el abuso de autoridad de la princesa. La narración no los critica como inmorales; al contrario: según Ex 1,20a.21 las parteras, p. ej., merecen la recompensa divina.

La fidelidad a la propia conciencia, por tanto, exige el recurso a medios, incluso extremos, para impedir el atropello de valores humanos fundamentales. Nadie queda eximido de responder a esta exigencia interior: de hecho, los medios de intervención están presentes en la simplicidad de la vida cotidiana.

Detengámonos todavía en una última consideración teológica acerca de Ex 2,1-10: el contexto donde se ubica, la liberación de los israelitas. La actuación de la hija del faraón reúne aspectos semejantes a la intervención divina en la gesta liberadora de Israel ${ }^{13}$ :

- Tanto la princesa como el Señor salvan a un inocente: han visto su penosa situación (cf. Ex 2,6a y Ex 2,25; 3,7a.8) y han escuchado sus gemidos (cf. Ex 2,6b $\beta$ y Ex 2,24; 3,7b-8).

13 T.E. Fretheim, Exodus, 38 estima incluso que estas actuaciones son directamente paralelas. 
- El motivo de las dos actuaciones es la compasión: la hija del faraón se conmueve ante un bebé indefenso y lo rescata (Ex 2,6b). El recuerdo $^{14}$ de su pacto con los patriarcas impulsa al Señor a la acción en favor de su pueblo (Ex 2,24; 3,6; 6,5) ${ }^{15}$. Además, cuando sobre el Israel pecador amenace la destrucción, Moisés apelará precisamente al recuerdo del pacto para detener el castigo decretado (Ex 32,13). El Señor cede (Ex 32,14; cf. Ex 33,19). En definitiva, el recuerdo de la alianza con los patriarcas enciende la compasión del Señor en favor de sus descendientes.

- Finalmente, el Señor y la princesa asisten a los recién salvados. La hija del faraón primero procura una nodriza al niño (Ex 2,7-10a). Se ocupa luego de la educación de su hijo adoptivo en su propio ambiente (Ex 2,10-11). El Señor, por su parte, sustenta al pueblo en el desierto (Ex 15,22-27; 16; 17,1-7); lo defiende de sus enemigos (Ex 17,8-16) y lo guía en el camino (Ex 13,21-22).

Sin embargo, hay un rasgo esencial que contradistingue las dos intervenciones: el Señor actúa conforme a un plan cuidadosamente preparado, escoge los instrumentos para la liberación (Ex 3-4). La hija del faraón acepta propuestas ajenas: es, p. ej., una hebrea quien le sugiere una nodriza de esa misma raza para el niño (Ex 2,7).

Examinemos la diferencia desde otra perspectiva, desde la relación entre el salvador y el rescatado. Ya antes de su rescate, Israel es el «hijo primogénito del Señor» (Ex 4,22-23). La liberación permite al pueblo inaugurar una comunión aún más personal, entrando en alianza con el Señor, convirtiéndose así en «su propiedad personal» (Ex 19,5). La decisión de la princesa de adoptar al niño como propio hijo, sigue, no precede, a la salvación del expósito. El niño rescatado no decide la adquisición de su nueva identidad.

Con todo, existe una cierta analogía entre lo que hace la princesa por Moisés y lo que el Señor está dispuesto a hacer por su pueblo ${ }^{16}$. Hay que

14 En el A.T., el verbo «recordar» (zk $\mathbf{k}$ ) usado en una afirmación y teniendo Dios o el Señor como sujeto, denota generalmente la conmovida percepción divina de la aflicción y/o pobreza de los hombres. P. ej.: Gn 8,1; 19,29; 30,22; Ex 2,24; Jr 31,20; S1 9,13; 78,39; 98,3; 136,23. Cf. H. EisING, «zāknar», TWAT, II, 571-593, espec. 578-581.

15 La «memoria» del Señor remite a la elección divina de los patriarcas; elección fruto de la iniciativa gratuita de un Dios compasivo. P. ej., con Abraham, anciano y sin hijos: Gn 15,1-6; 17; Is 41,8-14; 51,1-3.

16 R.J. Burns, Exodus, 25 extiende esta afinidad no solo a lo realizado por la princesa, 
suponer razonablemente, que los destinatarios conocen bien las tradiciones de la opresión y liberación de los israelitas en Egipto y, por lo mismo, asocian fácilmente la actuación de la hija del faraón en la salvación de Moisés a la futura liberación del pueblo, que él mismo guiará por voluntad expresa del Señor ${ }^{17}$. En concreto, la actitud fundamental de la hija del faraón, su compasión hacia el niño, su piedad maternal, evoca la compasión del Señor, actitud en que se fundamenta su acción en favor de Israel. El Señor no lo rescata de la esclavitud en atención a sus méritos, sino solo por su liberalidad (Ex 2,23-25). En este sentido el rescate de Moisés es una parábola de la liberación de Israel.

Cierto, la compasión no podía faltar tampoco en otros protagonistas de la escena: la madre natural y la hermana de Moisés. También la piedad maternal de estas mujeres reproduce a su modo la piedad de Dios con su hijo primogénito Israel (Ex 4,23): «¿Puede una madre olvidarse de su criatura, dejar de querer al hijo de sus entrañas? Pues, aunque ella se olvide, yo no te olvidaré» (Is 49,15) ${ }^{18}$.

La lectura reposada de Ex 1,15-2,10 pone de relieve el respeto y la promoción de la vida humana inocente. Su amenaza o el atentado contra ella interpela ineludiblemente a los seres humanos a dar una respuesta en

sino también a las intervenciones de la madre natural de Moisés y de su hermana mayor y a la participación de las parteras en el capítulo anterior.

17 Es particularmente sugestivo en este sentido, p. ej., el doble uso de sûp en Ex 2,1-10. No parece ser meramente casual; más bien es una referencia intencional a yam-sûp, «Mar de los Juncos» (cf. Ex 13,18). Cf. A. Ferrada Moreira, Nacimiento de Moisés, 138.

18 La analogía entre la piedad maternal de las mujeres de Ex 2,1-10 y la compasión divina puede iluminarse con Ez 16,1-7. Aquí el motivo del niño expósito quiere dibujar la formación de Israel como pueblo de Dios. Como en el caso de Ex 2,1-10, en Ez 16 tampoco basta la salvación del niño: el expósito queda envuelto bajo la protección divina; en el futuro, la neonata tendrá como padre al Señor.

Las semejanzas entre la parábola de Ezequiel y Ex 2,1-10 saltan a la vista: hallazgo de un niño abandonado, la custodia del protector hasta su madurez biológica. Pero sus diferencias no son menos importantes. El abandono en Ez 16 es brutalidad y desprecio: que el niño cargue a solas con su propia suerte, hasta donde llegue. La madre de Moisés, en cambio, intenta hasta lo último para salvar a su hijo (Ex 2,2b). El abandono es una decisión extrema y desesperada. Toma todas las precauciones para la supervivencia del neonato. (Ex 2,3-4).

De todos modos, en la metáfora de Ez 16, la reacción divina corresponde plenamente con la de la hija del faraón: piedad incondicional hacia un niño indefenso amenazado. Cf. A. Ferrada Moreira, Nacimiento de Moisés, 105. 
pos de su defensa y protección, pues es una experiencia primaria, común a todos, la no disponibilidad de la vida inocente al arbitrio humano. La inacción ante el mismo apelo, en cambio, repercute siempre negativamente en los seres humanos, aunque en diversos grados según las distintas circunstancias.

Esta interpelación es una experiencia íntima, sucede en lo que denominamos conciencia -la Biblia la llama simplemente corazón-. Ex 1,15-2,10 la iluminan mostrando narrativamente que para los creyentes no se trata de una vivencia puramente inmanente, sino también abierta a la trascendencia. En efecto, Dios interviene en ella dejando oír su voz, su voluntad; aunque en ciertos casos solo tenuemente pues, p. ej., es posible que se la intente silenciar.

Además, Dios deja sentir su voz en las conciencias de variadas formas. Ex 1,15-2,10 da cuenta de al menos dos vías: infundiendo temor en las parteras y compasión en las madres de Moisés y a su hermana mayor. Esta última consideración pone de manifiesto el desafío que enfrentamos: captar cómo Dios continúa hablando en el corazón de los hombres y las mujeres de hoy especialmente ante las sombras que se ciernen en contra la vida humana inocente. Este discernimiento es crucial para la evangelización en la hora presente. 


\section{Resumen}

El artículo hace una lectura atenta de Ex 1,15-2,10 poniendo de manifiesto que la salvación de los niños hebreos condenados a muerte por el faraón es obrada por la acción de Dios en la conciencia de las mujeres que los salvan; el Señor es agente indirecto de su rescate. En esta lectura se dejan ver dos principios fundamentales de la enseñanza moral cristiana: la vida humana inocente es un bien fundamental e indisponible bajo ninguna circunstancia y su no disponibilidad se capta en la conciencia, sagrario donde Dios se revela a todo ser humano. Finalmente el artículo profundiza en el mensaje teológico del pasaje veterotestamentario.

\section{Palabras clave}

Pentateuco, Éxod, Vida, Vida humana, Vida inocente, Conciencia, Voz Divina, Voluntad Divina, Temor a Dios (Aborto, Infanticidio, Eutanasia, Derechos Humanos), Poder público.

\section{Summary}

The article makes a careful reading of Ex 1, 15 - 2, 10, making clear the fact that the salvation of the Hebrew children sentenced to death by the Pharaoh is made by the action of God in the conscious of the women who save them; the Lord is the indirect agent of their rescue. This reading permits two fundamental principles of Christian moral teachings to be seen: innocent human life is a fundamental right, not available under any circumstances and its non availability is captured in the conscious, the sacred tabernacle where God reveals Himself to every human being. Finally the article delves into the theological message of this Old Testament passage.

\section{Key Words}

Pentateuch, Exodus, Life, Human Life, Innocent Life, Conscience, Divine Voice, Divine Will, Fear of God (Abortion, Infanticide, Euthanasia) (Human Rights), Public Power. 